Anna A. Sher · Deborah E. Goldberg •

Ariel Novoplansky

\title{
The effect of mean and variance in resource supply on survival of annuals from Mediterranean and desert environments
}

Received: 1 July 2003 / Accepted: 20 October 2003 / Published online: 11 December 2003

(C) Springer-Verlag 2003

\begin{abstract}
Resource availability is often characterized by mean annual amounts, while ignoring the spatial variation within habitats and the temporal variation within a year. Yet, temporal and spatial variation may be especially important for identifying the source of stress in low productivity environments such as deserts where resources are often pulsed and resource renewal events are separated by long periods of low resource availability. Therefore, the degree of stress will be determined in part by the length of time between recharge events. Here, we investigated the effect of timing and total amount of water application on two congeneric pairs, each with a population from a low (desert) and a high (Mediterranean) productivity habitat. As expected, highest survival and greatest growth were found at low or intermediate recharge intervals, and the magnitude of response to increases in total seasonal amounts was greater for Mediterranean species than desert species. The species that had greater survival switched in the hierarchy under high total water depending on interval length. These results demonstrate that temporal variation in resource availability can be as important as annual total amounts for plant performance and that response to temporal dynamics can vary between species. This has implications for community-level processes, as competitive hierarchies may switch based on resource dynamics rather than only total availability.
\end{abstract}

A. A. Sher $(\bowtie) \cdot$ D. E. Goldberg · A. Novoplansky

Mitrani Department of Desert Ecology, Blaustein Institute for

Desert Research, Ben Gurion University of the Negev,

84990 Midreshet Ben Gurion, Israel

e-mail: asher@du.edu

D. E. Goldberg

University of Michigan,

Ann Arbor, MI 48109, USA

Present address:

A. A. Sher

Department of Biological Sciences, University of Denver,

Denver, CO 80208, USA
Keywords Temporal resource availability $\cdot$ Pulse dynamics · Phenotypic plasticity · Desert ecology · Drought resistance

\section{Introduction}

In unproductive desert habitats, water availability is often highly pulsed, with both infrequent and irregular water availability (Cable 1969; Noy-Meir 1973; Evenari et al. 1982; Knapp and Smith 2001). The importance of this irregularity to plant growth and/or survival is often considered in terms of inter-year (e.g., Knapp and Smith 2001) or inter-seasonal variation [e.g., winter versus spring rainfall; e.g., Welzin and McPherson (2000); Schwinning and Erhlinger (2001)]. However, within-season dynamics of precipitation can be at least as or more important than the seasonal or annual total for plant growth (Fay et al. 2000; Novoplansky and Goldberg 2001a; Knapp et al. 2002) and abundance of plant functional types (Reynolds and Kemp 2002). Previous studies have also demonstrated a similar large effect of temporal heterogeneity of nutrients (Campbell and Grime 1989; Miao and Bazzaz 1990; Bowman 1992; Lodge et al. 1994; Bilbrough and Caldwell 1997). However, the data for water suggest somewhat different patterns in response to water pulses than nutrient pulses: whereas large, infrequent nutrient pulses have been found to be best for plant growth, work on water pulsing found the highest photosynthetic rates (Knapp et al. 2002), greatest growth rates of individuals (Novoplansky and Goldberg 2001a), and greatest primary productivity (Fay et al. 2000; Knapp et al. 2002) under frequent and small pulses of water. Global climate change appears to be resulting in shifts toward larger, less frequent rain events, thus making it imperative to understand how different species may be impacted by temporal variation in water supply (Easterling et al. 2000).

For both water and nutrient pulses, most work to date has focused on consequences for physiological parameters or net growth of individual plants (e.g., Miao and Bazzaz 1990; Ehleringer et al. 1991; Novoplansky and Goldberg 
2001a; Gebauer et al 2002; but see Novoplansky and Goldberg 2001b; Knapp et al. 2002). However, survival might show quite different responses than growth, especially when water is the pulsed resource, because of increased mortality during long periods of drought between resource renewal events. Whereas growth during pulses may be determined in part by uptake rates, survival between pulses may be governed by other processes such as a plant's ability to initiate physiological dormancy (e.g., desert mosses), to store water in tissues (e.g., succulents), or access deep soil water (Schwinning and Ehleringer 2001). If size before drought onset is not strongly correlated with these adaptations, we might expect growth and survival to be decoupled responses (Goldberg and Novoplansky 1997).

In their "two-phase resource hypothesis", Goldberg and Novoplansky (1997) made this distinction between the periods when resources are available ("pulse") and when resources are too low for plant use ("interpulses"), during which time most mortality will occur. The theory states that in low productivity environments, these interpulses may be the primary environmental factor to which plants respond, possibly superseding in importance the dynamics that take place during pulses. At what point after the recharge event the pulse ends and the period when plants can no longer uptake water begins will likely vary between species and even individuals. Interpulse is therefore a difficult variable to manipulate in an experimental setting. However, it has been shown that lengthening the time between recharge events within a season can increase the number of dry days (i.e., interpulse length), even when total water is kept constant (Fay et al. 2000, Knapp et al. 2002). Thus, we may increase the interpulse by lengthening the inter-recharge periods, or "recharge intervals". This effect should be heightened in hot, dry environments where evaporation from the soil surface is great (Noy-Meir 1973).

The relationship between inter-recharge length and plant stress may not be linear, however, and when/if the interpulse is reached is likely to vary between plants. Therefore it is necessary to test a range of recharge intervals for different species. Differential species response to changes in intra-season recharge frequency has been documented only for grassland species (Fay et al. 2000, Novoplansky and Goldberg 2001a, Knapp et al. 2002). For any ecosystem or species, size and frequency of water pulses will be irrelevant both above some saturation point and below a level usable by the plant; therefore, biologically meaningful variation in water pulsing should occur at some intermediate level of pulse size and frequency. This work will investigate plant response to a range of intervals for sand dune species.

Here, we compare the effect of seasonal totals of water versus recharge intervals of annuals for survival and for growth. These comparisons were made for congeneric pairs, with one species from an arid habitat where recharge events are highly variable, sometimes long, and the seasonal totals are low, and a related species or population from a Mediterranean habitat where pulses are more frequent and predictable, and seasonal totals are high. If time between recharge events poses an important source of stress, we would expect local adaptation to pulsing regime. Abundant research on desert versus Mediterranean congeneric species has documented the potential for local adaptation to water stress (Taub and Goldberg 1996; Sternberg and Shoshany 2001; Nilsen and Sharifi 1997; Volis et al. 2001, 2002), thus making this an ideal system for investigating the potential for adaptation to the temporal aspect of water availability.

Therefore, we should detect differences between species in response to varying interval lengths, even under constant seasonal totals. If, on the other hand, seasonal totals are more important than temporal distribution, only total water amount should be important for predicting survival and growth and for distinguishing sources of the plants. In terms of fitness, survival is only a relevant response if a plant has reproduced within its lifetime. Therefore, we are most interested in survival to reproduction when we discuss mortality as a response.

This experiment tests the hypotheses that number of days between resource renewal events can be as important as seasonal totals of water for survival and growth, that total water and interval will interact, and that species will differ in their responsiveness to these variables. Accordingly, we address the following specific questions and predictions regarding the role of pulsing regime and total resource supply on plant demography:

1. How does pulsing regime influence plant survival? Is this effect as large in magnitude as the effect of changing the annual amount of resource available?

When the total water supply is high, we predict that premature mortality due to drought will increase with increasing intervals between pulses, i.e., presumably an increasing interpulse length. However, when the total amount of water is low, we predict that plants will have highest survival at an intermediate interval duration because of the inevitable confounding of interval length and individual pulse size when total resource supply is constant: very short recharge intervals will necessarily have very small individual pulses and these may become too small for plants to use (Noy-Meir 1973).

2. Are the responses to pulsing different for survival and growth?

As discussed above, if mortality is simply the ultimate expression of decreased growth, we would expect the same patterns of interaction between recharge interval and total water as was predicted for survival patterns; i.e., greatest growth at frequent pulsing for high total precipitation, and greatest growth at intermediate recharge rate for low total precipitation. However, increases in size should take place only during pulses and to keep the annual total constant in this experiment, individual pulses are necessarily larger with longer intervals. Thus, it is possible that growth may increase with increasing interval, i.e., the pattern for growth would be the opposite of that for survival. On the other hand, the stress of infrequent 
recharge may cause a plant to lose parts and actually become smaller, suggesting that growth and survival will show similar responses.

3. Does source habitat determine degree of responsiveness to pulsing regimes?

Adaptation to stress is often associated with conservative growth manifested in a lower ability to respond to increased resource availability (e.g., CAM plants), and so species adapted to deserts (or other stressful habitats) may have physiological constraints that prevent them from responding to increases in resource availability (Chapin 1991; Grime 2001). For example, previous work comparing response to water levels in xeric and mesic habitat species from a New Mexico grassland found less responsiveness to increased water in the xeric than in the mesic species (Novoplansky and Goldberg 2001a). A similar reduction in responsiveness was also found in desert relative to Mediterranean congeneric species in
Israeli grasses (Volis et al. 2001). Species from more productive habitats should be highly sensitive to changes in total annual precipitation and interpulse length, since they are not adapted to tolerate long periods of drought, and because they are selected to be more responsive to high resources when available. Therefore, we predict that for both survival and growth, Mediterranean plants will be more responsive to increases in total water availability than will desert plants.

4. Is there local adaptation to a pulsing regime such that plants from each source perform best under typical conditions of that habitat?

If both total water and pulsing regime are important selective forces, we expect that under low water (regardless of pulsing) or under long recharge intervals (regardless of total water) the desert species should survive better
Fig. 1 Diagram of the eight watering treatments to illustrate the relationship between mean pulse size (varying from 2.5 to $81.6 \mathrm{~mm}$ ), number of watering events $(n=3-24)$, interval length $(3,6,12$, or 23 days $)$, and total amount of watering over the season (high $=328 \mathrm{~mm}$, right column, and low $=206 \mathrm{~mm}$, left column). Peaks indicate watering events. Note that two pulse sizes (10.2 $\mathrm{mm}$ and $20.4 \mathrm{~mm})$ are represented in both high and low water categories, thus allowing comparisons of effects of pulse size. Significant events in the chronology of the experiment across treatments from date of planting are indicated by numbered arrows. $1 \rightarrow$ Erodium begins germinating, $2 \rightarrow$ Vulpia begins germinating, $3 \rightarrow$ seedlings are transplanted, $4 \rightarrow$ first size measurements taken, $5 \rightarrow$ mean date of first flower for both desert and Mediterranean Erodium, $6 \rightarrow$ mean date of flowering for desert Vulpia and second size measurements taken, $7 \rightarrow$ mean date of mortality for both desert Erodium and Vulpia, $8 \rightarrow$ sampling biomass of dying plants begins, 9 $\rightarrow$ mean date of mortality for Mediterranean Erodium and Mediterranean Vulpia, $10 \rightarrow$ mean date of flowering for Mediterranean Vulpia, $11 \rightarrow$ final harvest of biomass of remaining living plants, Jan January, Feb February, Mar March, Apr April
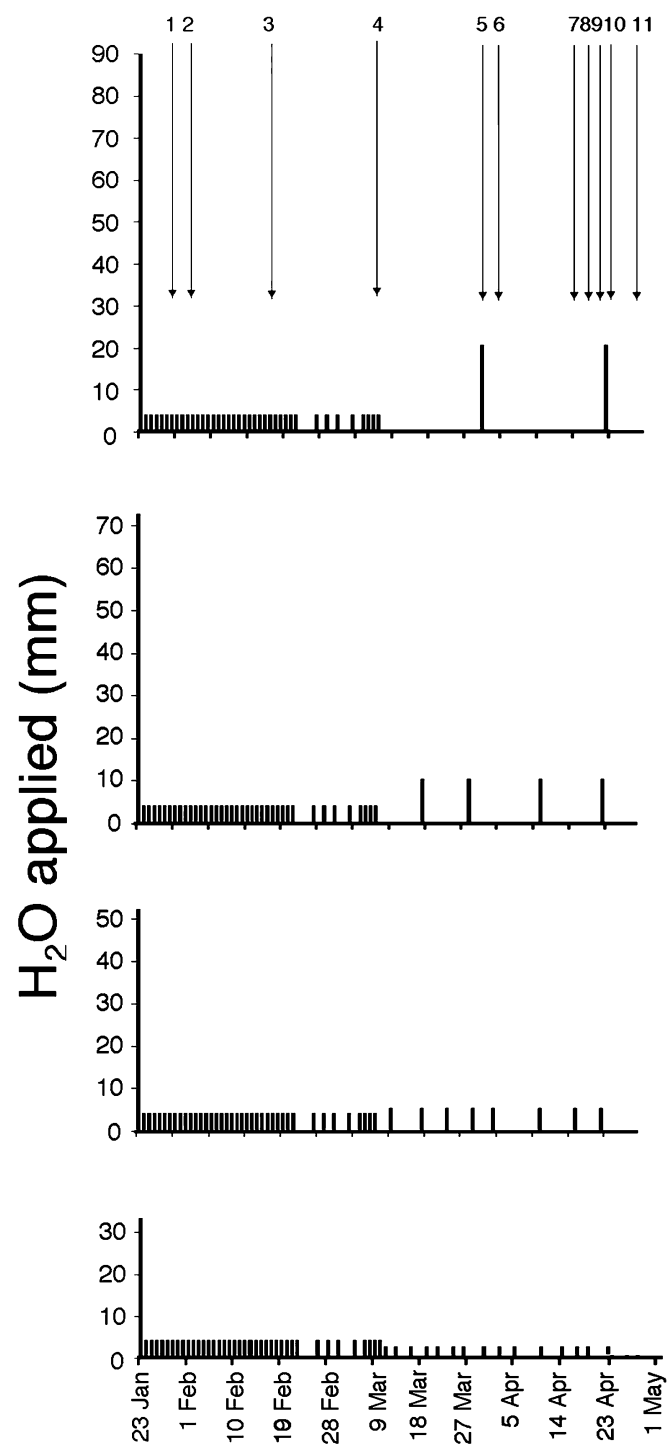

Date
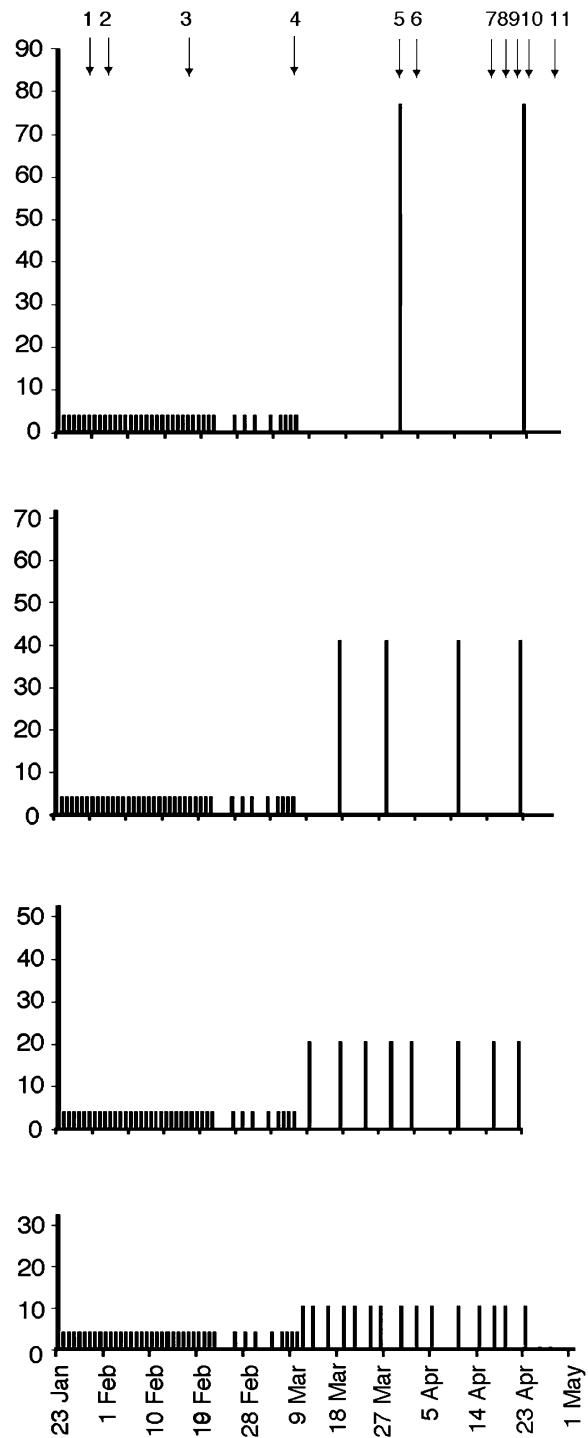
than the Mediterranean species. However, we predict that Mediterranean species will be better at exploiting a high amount of water and short intervals.

\section{Materials and methods}

This research was conducted in the ecological growth facility at the Sde Boqer campus of Ben Gurion University of the Negev, Israel. This structure has sides that are open during daylight, when it is not raining, and protection against extreme temperatures, rain and morning dew. We grew two congeneric species pairs from desert and Mediterranean habitats across a range of water regimes. These were a grass, Vulpia brevis Bioss \& Ky. (Feinbrun-Dothan 1986) and $V$. myuros (L.) (Feinbrun-Dothan 1986), from desert and Mediterranean habitats, respectively, and a forb, Erodium laciniatum (Cav.) Willd. (Zohary 1972), from both sources. Because the two Erodium populations are the same species, while the Vulpia populations are truly distinct species, the plants from the different source habitats will henceforth be referred to as "Mediterranean" and "desert" plants for the sake of simplicity.

Seeds were collected from a desert site at Holot Mashabim $\left(31^{\circ}\right.$ $00^{\prime} \mathrm{N} 34^{\circ} 44^{\prime} \mathrm{E} ; 110 \mathrm{~mm} /$ year precipitation), a nature reserve in the Negev and from a Mediterranean site near the coast at Caesarea $\left(32^{\circ}\right.$ $30^{\prime} \mathrm{N} 34^{\circ} 55^{\prime} \mathrm{E}$; $550 \mathrm{~mm} /$ year precipitation) in the spring of 1998 . Seeds of each species were planted in Styrofoam transplant flats filled with sand on 22 January 1999 and watered daily. Date of germination was recorded for each plant. Plants were transplanted to treatment pots when germination reached at least $50 \%$ for each species, on 17 February. Pots were made of opaque $150-\mu$ m-thick polyethylene sleeves (Ginnegar Plastics, Israel). Pots were $25 \mathrm{~cm}$ tall and $10 \mathrm{~cm}$ in diameter, with four $1-\mathrm{cm}$ drainage holes at the bottom. The pot sleeve was folded at the bottom to prevent sand from escaping out of the holes while allowing water drainage. Each pot was filled with seed-free sand collected near the desert source site. No fertilizers or organic matter were added. All treatment pots were lightly watered (approximately $5 \mathrm{~mm}$ ) daily for 1 week, and then every 1-3 days for 2 weeks following planting, according to observed stress to plants. Dead seedlings were replaced with new transplants during this time as necessary. Pulse treatments were initiated on 9 March, after mortality rates had decreased to less than $1 \% /$ day.

Three inter-dependent variables determine resource availability: (1) total seasonal amount, (2) pulse size or the amount of each renewal event, and (3) the time between renewal events. Only two of these variables can be manipulated independently, e.g., for a given seasonal total, increasing the frequency of pulses means that each pulse must be smaller. We focused our predictions and interpretation on the interaction between total seasonal amount and recharge interval. However, while treatments are described below in terms of interval length, it is important to remember that greater interval length necessarily also means a larger pulse (Fig. 1). To partially address this inevitable, confounding effect, we also designed our treatments so that comparisons could be made between two groups with the same pulse sizes, but differing recharge intervals and therefore seasonal totals.

Treatments included eight water regimes: four different intervals, each at low or high total water availability (Fig. 1). Interval length was calibrated to evaporative water losses such that the degree of stress of each treatment remained similar throughout the experiment, despite increasing radiation and temperatures near the end of the growing season. Thus, pots were watered after $1.5,3,6$, or $12 \mathrm{~mm}$ of evaporation from an open pan in the greenhouse. These treatments corresponded to mean intervals over the entire season of $3,6,11$, and 23 days. The experiment was designed such that all treatments, including the high water, large pulse treatments $(640 \mathrm{ml})$, were below soil field capacity (full field capacity was estimated as $800 \mathrm{ml}$ for this soil and pot size). After initiation of the experiment, each high $\times$ interval treatment received 4 times the amount of water of the corresponding low $\times$ interval treatment. However, as all plants received the same amount of water during germination and initial
Table 1 Logistic regression to test probability of mortality before reproduction for each genus. Independent variables are: water level (high vs. low season totals), interval (3, 6, 12 or 23 days), and source (desert vs. Mediterranean)

\begin{tabular}{llll}
\hline Source & $d f$ & $\begin{array}{l}\text { Vulpia } \\
X^{2}\end{array}$ & $\begin{array}{l}\text { Erodium } \\
X^{2}\end{array}$ \\
\hline Water & 1 & $8.19^{* *}$ & $4.52^{*}$ \\
Interval & 3 & $10.78^{* *}$ & $1.20 \mathrm{NS}$ \\
Source & 1 & $11.54^{* * *}$ & $0.17 \mathrm{NS}$ \\
Water $\times$ interval & 3 & $3.93 \mathrm{NS}$ & $13.20^{* *}$ \\
Water $\times$ source & 1 & $17.32^{* * *}$ & $0.05 \mathrm{NS}$ \\
Interval $\times$ source & 3 & $10.96^{* *}$ & $11.10^{* *}$ \\
Water $\times$ interval $\times$ source & 3 & $2.66 \mathrm{NS}$ & $3.32 \mathrm{NS}$ \\
\hline
\end{tabular}

$* * * P<0.001,{ }^{* *} P<0.01, * P<0.05, N S$ not significant $(P>0.05)$

establishment, true seasonal totals for low and high treatments differed by a smaller degree: approximately $206 \mathrm{~mm}$ and $328 \mathrm{~mm}$, respectively.

In all, there were 32 different treatments: two genera $\times$ two sources $\times$ two total water levels $\times$ four interval lengths, each replicated 30 times for a total of 960 plants. Plants were individually planted in pots and were arranged in a randomized block design, based on the size and arrangement of benches available: each block was a bench, representing the south-north axis of the growth facility. There were a total of 13 blocks: two replicates of each treatment randomized by location in each of nine blocks (=18 of 30 replicates), and three replicates randomized in each of four blocks (=12 of 30).

Mortality and flowering were monitored every 3 days until the last 2 weeks of the experiment, when they were recorded daily. Date of first flowering was recorded when the first flower fully matured, and a plant was scored as dead when it bore no living, photosynthesizing tissue. Plants were classified as having survived to reproduction if seeds were produced by the time of mortality or by the end of the end of the experiment, which corresponded to the end of the growing season in the field. Reproduction was not quantified. Size (height and number of leaves) was measured 3 times at monthly intervals. From 19 April, when there was high mortality across treatments, plants were harvested for aboveground biomass as they died by clipping at the base. At the end of the growing season (28 April), all remaining, surviving plants were harvested for aboveground biomass, and a sub-sample of five pots per treatment was harvested for belowground biomass. Biomass was measured after drying the plants in a ventilated oven at $60^{\circ} \mathrm{C}$ for 5 days.

The effect of water amount (high, low), interval, and source (desert or Mediterranean) on probability of surviving to reproduction was analyzed using a multiple logistic regression (PROC GENMOD, SAS 1990). The effect of these independent variables on relative growth rate (RGR), aboveground biomass, belowground biomass, and root:shoot ratio were analyzed using ANOVAs (PROC GLM, SAS 1990). Linear regressions of final biomass against final height (or height $\times$ leaf number) were usually not significant, making it impossible to estimate biomass of plants before the final harvest. Instead, we calculated RGR based on the change in height between the time $(t)$ when treatments were begun (t1: 10 March 1999) and height after one 23-day cycle of all treatments, when all plants within a water treatment had received the same, cumulative amount of water ( $t 2$ : 3 April 1999), assuming linear growth [( $t 2-t 1) /$ days] We did not analyze change in height over the second cycle (to 27 April 1999) because, by this time, most plants of both genera had finished their life cycle and either died or had begun to deteriorate. Thus, sample sizes were too small in some treatments to consider the effects of all treatments on growth. Similarly, we view data on height growth over the first cycle as more reliable than final biomass because of relatively small sample sizes of surviving plants in some treatments at the final harvest. 
Change in leaf number over time was analyzed using a repeated measures MANOVA (PROC GLM, SAS 1990), comparing differences in the effect of time between sources and treatments for each genus over the entire sampling period; however, interactions between treatments could not be tested due to loss of sample size by the third sampling period. The relationship between lifespan and initial size was determined using linear regressions. All dependent variables were tested for normality and biomass measurements (total biomass, root biomass, root:shoot ratio) were log-transformed to improve normality.

In the above analyses, the importance of pulsing regime and total water for growth and survival are reflected by the significant main effects and interactions involving recharge interval or total water. Differences in responsiveness between Mediterranean and desert sources are reflected by significant source by water, or source by interval effects, on growth and survival. Specific predictions of direction of response and relative magnitudes of effect are tested by the statistical tests combined with the visual analysis of responses.

\section{Results}

Effects of pulsing regime and total water on survival

Time between recharge events, total water amount, and source were all important for explaining patterns of survival to reproduction, with significant main or interactive effects for both Erodium and Vulpia (Table 1). For Mediterranean plants, the results were exactly as predicted a priori: increasing total water significantly increased survival for both genera (Table 1, Fig. 2), and increasing inter-recharge length led to declining survival at high total water. However, at low total water, frequent pulsing was also unfavorable, leading to peak survival at intermediate intervals for both genera (Fig. 2).

In contrast, for desert plants of both genera, the effects of total water supply and pulsing regime agreed less consistently with predictions and were more complex. For desert Vulpia, both high and low water conditions resulted in peak survival at intermediate recharge intervals, rather than only under low water as initially predicted in general

Table 2 ANOVA test results on log-transformed total biomass, final root biomass, and relative growth rate $(R G R)$ based on height by source, total water level, and interval length for Erodium and forVulpia. Error $d f$ are given for each analysis; sample sizes differ and as found for Mediterranean plants. This result is reflected in the significant source by interval interaction (Table 1, Fig. 2). For desert Erodium, results were also surprising, with the highest survival at the longest interval for both high and low water, which was inconsistent with both predictions and the observed results for Mediterranean plants. However, consistent with predictions, only at low water was there a strong negative effect of the very short intervals on survival, presumably due to the corresponding very small size of individual pulses. In some cases for both desert populations, survival was actually better at low, rather than high, total water (Fig. 2).

\section{Effects of pulsing regime and total water on growth}

Effects of total water and recharge interval on total biomass or root biomass at the end of the season were both relatively minor (Table 2). For total biomass, the only significant effects other than source (see below) were higher total biomass at high total water relative to low total water for Vulpia, and a significant interaction for total biomass between interval and total water for Erodium, such that at low total water, there was no difference between pulsing frequencies, but at high total water, there was an increase in biomass at an intermediate interval length (Table 2; A. A. Sher et al., unpublished data). For root mass, only Vulpia showed any significant effects of treatments, with significant interactions between source and interval and source and water (Table 2). These interactions reflected the fact that, for Mediterranean Vulpia, root mass increased with interval length and with high total water, whereas desert Vulpia had greatest root mass under an intermediate pulsing frequency and did not respond to total water (data not shown).

Effects on height RGR during the month after treatment initiation were somewhat stronger than on biomass accumulation over the season, with significant effects of

because root biomass was sub-sampled and because not all plants survived for final biomass measurements. $F$ - and $P$-values were calculated from type III sums of squares

\begin{tabular}{|c|c|c|c|c|c|c|c|}
\hline \multirow{2}{*}{$\begin{array}{l}\text { Response variable } \\
\text { Factor }\end{array}$} & \multirow[t]{2}{*}{$d f$} & \multicolumn{2}{|c|}{ Log (total biomass) } & \multicolumn{2}{|c|}{$\underline{\log \text { (root biomass) }}$} & \multicolumn{2}{|l|}{ RGR } \\
\hline & & $\begin{array}{l}\text { Erodium }(d f=129) \\
F\end{array}$ & $\begin{array}{l}\text { Vulpia }(d f=87) \\
F\end{array}$ & $\begin{array}{l}\text { Erodium }(d f=89) \\
F\end{array}$ & $\begin{array}{l}\text { Vulpia }(d f=66) \\
F\end{array}$ & $\begin{array}{l}\text { Erodium }(d f=264) \\
F\end{array}$ & $\begin{array}{l}\text { Vulpia }(d f=231) \\
F\end{array}$ \\
\hline Bench & 12 & $1.02 \mathrm{NS}$ & $2.09 *$ & $0.518 \mathrm{NS}$ & $2.28 *$ & $3.77 * * *$ & $1.81 *$ \\
\hline Source & 1 & $34.97 * * *$ & $12.06 * * *$ & $0.265 \mathrm{NS}$ & $7.64 *$ & $109.58^{* * *}$ & $10.02 * *$ \\
\hline Interval & 3 & $1.30 \mathrm{NS}$ & $0.74 \mathrm{NS}$ & $0.320 \mathrm{NS}$ & $0.38 \mathrm{NS}$ & $3.86^{* *}$ & $2.83 *$ \\
\hline Water & 1 & $0.57 \mathrm{NS}$ & $7.33 * *$ & $0.469 \mathrm{NS}$ & $0.00 \mathrm{NS}$ & $0.13 \mathrm{NS}$ & $1.15 \mathrm{NS}$ \\
\hline Source $\times$ interval & 3 & $1.31 \mathrm{NS}$ & $0.80 \mathrm{NS}$ & $0.053 \mathrm{NS}$ & $3.41 *$ & $0.56 \mathrm{NS}$ & $0.85 \mathrm{NS}$ \\
\hline Source×water & 1 & $0.01 \mathrm{NS}$ & $0.22 \mathrm{NS}$ & $0.376 \mathrm{NS}$ & $4.82 *$ & $1.64 \mathrm{NS}$ & $0.97 \mathrm{NS}$ \\
\hline Interval $\times$ water & 3 & $3.03 *$ & $1.64 \mathrm{NS}$ & $0.444 \mathrm{NS}$ & $0.32 \mathrm{NS}$ & $3.60 * *$ & $1.79 \mathrm{NS}$ \\
\hline Source $\times$ interval $\times$ water & 3 & $1.13 \mathrm{NS}$ & $0.40 \mathrm{NS}$ & $0.165 \mathrm{NS}$ & $0.55 \mathrm{NS}$ & $0.83 \mathrm{NS}$ & $0.11 \mathrm{NS}$ \\
\hline Total model & 22 & $2.89 * * *$ & $2.64 * * *$ & $0.670 \mathrm{NS}$ & $1.77 *$ & $6.97 * * *$ & $1.87 * *$ \\
\hline
\end{tabular}

$* * * P<0.001, * * P<0.01, * P<0.05, N S P>0.05$ 
Fig. 2 Percent survival to reproduction across interval lengths and total water levels (high $=500 \mathrm{~mm} / \mathrm{season}, \mathbf{-}$-; low $=100 \mathrm{~mm} / \mathrm{season},-\mathrm{-}-$ ) for B) vs. desert (C, D)] within each genus [Vulpia $(\mathbf{A}, \mathbf{C})$ vs. Ero$\operatorname{dium}(\mathbf{B}, \mathbf{D})]$ each source [Mediterranean (A,
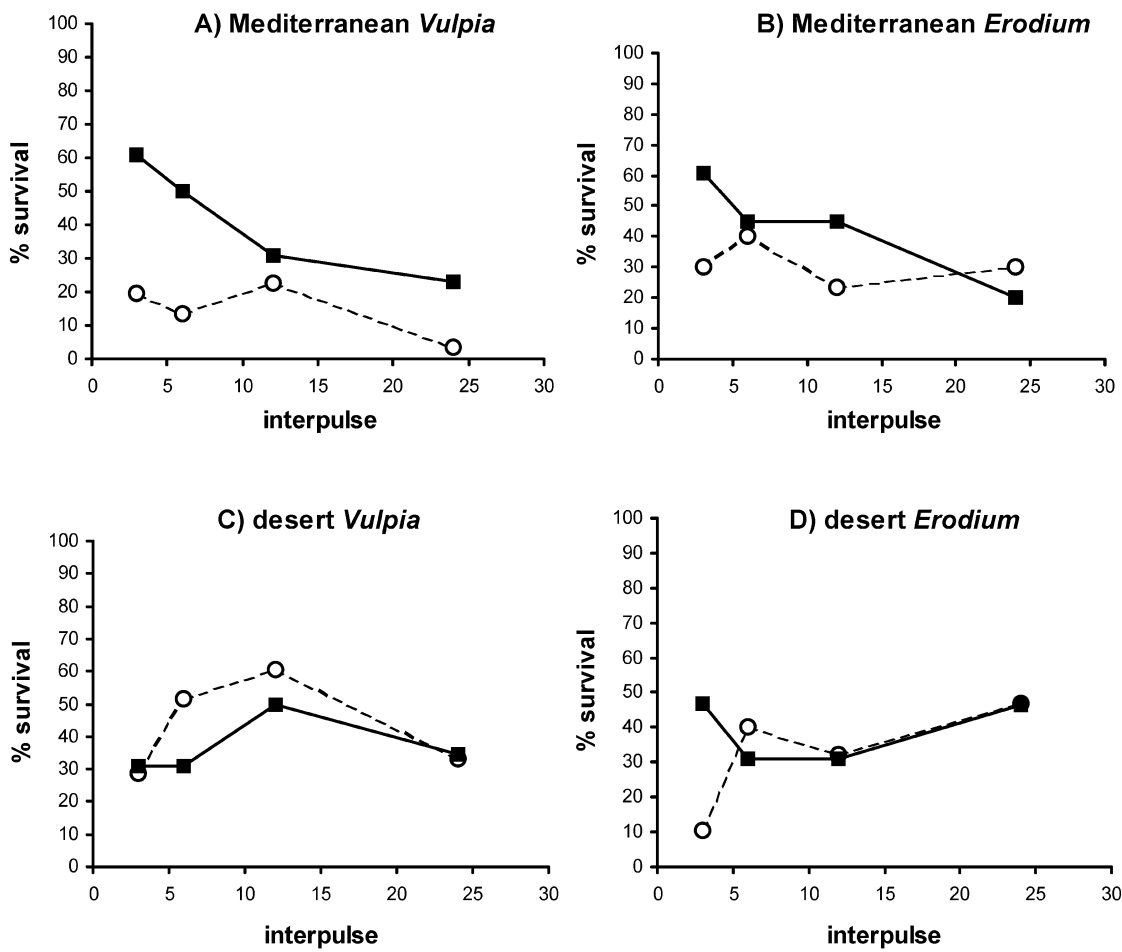

recharge interval for both genera and a significant water by interval interaction for Erodium (Table 2). While source populations differed in height growth overall (see below), there were no interactions involving source (Table 2), so that results are shown averaged across sources in Fig. 3. Overall, height growth during this period of resource variability was positive for Erodium, but negative for Vulpia, regardless of treatment or source (Fig. 3). Increasing interval length (and pulse size) significantly decreased height RGR for both species (Fig. 3). For Erodium, height RGR decreased with increasing intervals, but at low total water, growth was also reduced under frequent (and small) pulses, similar to the response of survival (Table 2, Fig. 3a).

The negative height growth of Vulpia is probably because height was measured as the vertical extension of the longest leaf in this grass and leaves were often lost during the time between recharge events. To test this, we used a repeated measures analysis of leaf number in Vulpia over the entire experiment. Vulpia leaf number varied significantly over time, with the general pattern of maintenance of leaf number in the first month following initiation of the treatments, but a loss of leaves in the second month (MANOVA, test for effect of time, Wilks $\lambda$, $\left.F_{2,104}=4.35, P<0.02\right)$. However, patterns of leaf numbers over time differed between interval treatments (timex interval, $\left.F_{6,208}=2.6, P<0.02\right)$ such that the different intervals' rank in leaf number reversed during the second month. The plants with the longest recharge interval lost the most and had the fewest leaves after 1 month, but recovered in the second month to have the most leaves at the end of the experiment. Source populations did not differ in sequence (time ${ }^{\circ}$ source, $F_{2,104}=1.35, P<0.27$ ). Like Vulpia grown with frequent pulses, Erodium gained
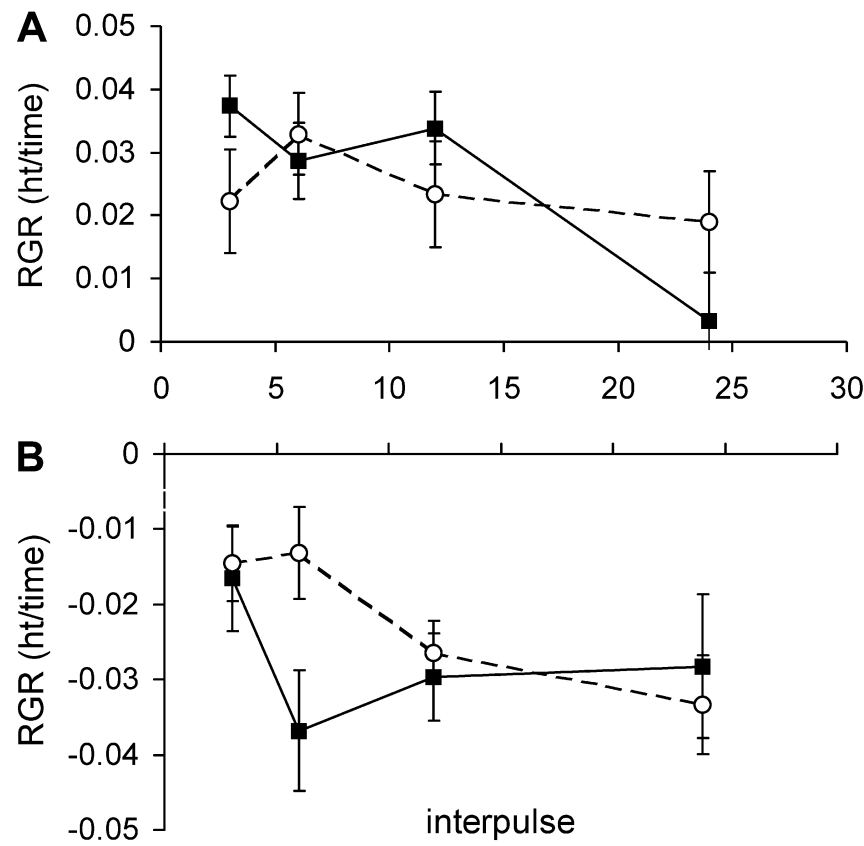

Fig. 3 Mean relative growth rates $(R G R)$ of height $( \pm 1 \mathrm{SE})$ during the first month after treatment initiation as a function of interval length for A Erodium and B Vulpia. Data are averaged across sources for low (-०-) vs. high water levels (-口-)

and then lost leaves (effect of time, $F_{2,91}=8.34, P<0.001$ ); however, there were no significant interactions between time and other experimental factors.

Root:shoot ratio was not significantly affected by source, water, or interval length, nor any of their interactions (A. A. Sher et al., unpublished data). 
Source effects

Survival rate appeared to switch between the source of the plants, depending on total amount of water and recharge interval, for both genera (Table 1). Figure 4 allows a visual comparison of survival between the two sources across usable pulses (i.e., the upper and lower bound of interval lengths, excluding the smallest pulse). Results supported predictions that Mediterranean source plants would survive better than desert plants under high total water and frequent pulses, whereas at low total water, the desert species generally survived better than the Mediterranean species, regardless of interval length. At high water levels for both genera, the plants from Mediterranean sources had the highest survival with short recharge interval periods, while the plants from desert sources had the highest survival with the longest intervals. Desert plants also generally died earlier than the Mediterranean plants (Fig. 1).

In contrast to these results for survival, for both genera, Mediterranean plants grew faster in height and accumulated more total biomass than did desert plants, regardless of total water amount or recharge interval length, i.e., had no significant interactions involving source (Tables 2, 3).
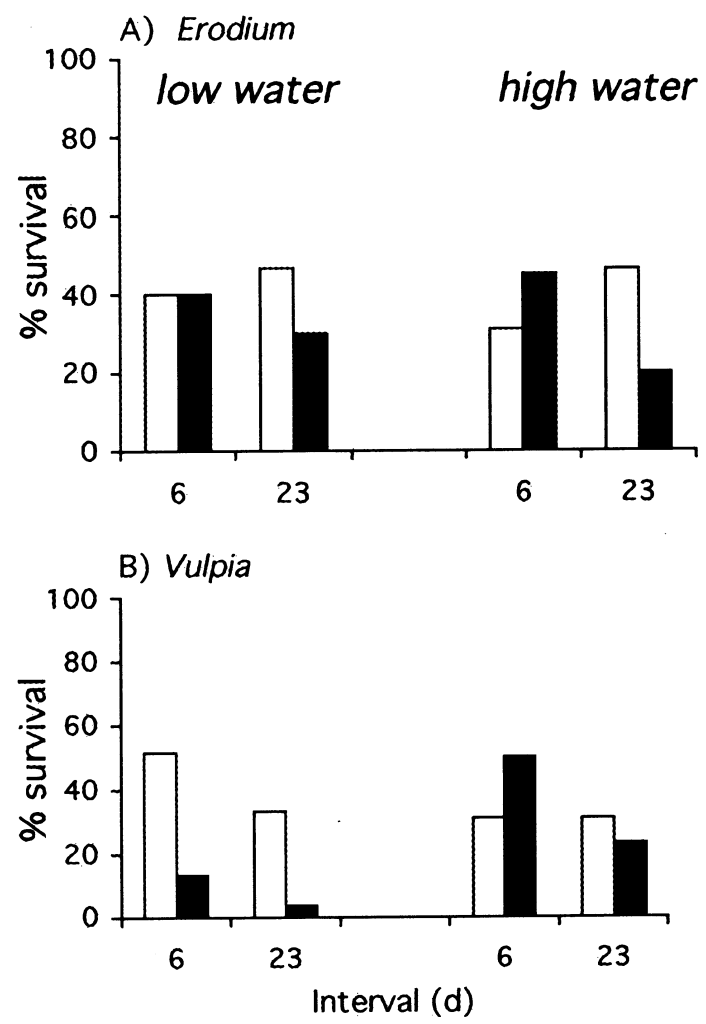

Fig. 4 Percent survival vs. reproduction of desert source (white bars) and Mediterranean source (black bars) Vulpia and Erodium plants grown at either short or long intervals and high or low water levels. Individual pulse size is $20.4 \mathrm{~mm}$ both in the 23-day interval, low water treatment and in the 6-day interval, high water treatment
Effects of pulse size

We designed our experiment to focus on effects of total water and interval length between recharge events; however, limited comparisons between pulse sizes could be made as well. If pulse size was more important than either total water or interval length, we might expect species survival hierarchies to be determined by pulse size, even as the other factors varied. However, for both genera, the survival hierarchy switched between Mediterranean and desert plants for pulse sizes of $20.4 \mathrm{~mm}$ but with different total water and interval lengths (in Fig. 4, compare low water, 23-day interval with high water, 6-day interval). However, low survival rates under small pulses show that this is not an irrelevant variable.

\section{Effect of initial size on survival}

We tested the relationship between initial size of a plant and length of life on individuals that did not survive to the end of the experiment. Initial size had no relationship with life span for either Erodium, or the desert Vulpia; out of the four populations we studied, only Mediterranean Vulpia had a significant, positive relationship between initial size and life span (linear regression, $F_{1,42}=8.09$, $P>0.007$, adjusted $R^{2}=0.14$ ). However, plants that lived to the end of the experiment were significantly larger at the initiation of treatments than plants that did not survive, for both Mediterranean Vulpia (ANOVA, $F_{1,149}=13.04$, $P<0.0004)$ and Mediterranean Erodium $\left(F_{1,140}=7.56\right.$, $P<0.007$ ), while initial size had no significant effect on survival for the desert source plants.

Although not of primary interest, analysis was also done on time to flowering. Time to flowering was more variable for Mediterranean plants than desert plants, and desert Vulpia flowered earlier than Mediterranean Vulpia (Fig. 1), but in no case did treatments significantly explain variation in phenology of flowering.

\section{Discussion}

The results for both genera support the hypothesis that the temporal aspect of resource renewal can have significant effects on both plant growth and survival, even while total resource levels or individual pulse sizes are held constant, and that these two aspects of resource availability may interact differently for different species. A sixfold increase in the amount of time between recharge events made survival to reproduction less than half as likely for both of the Mediterranean populations tested, and decreased RGR by $>50 \%$ for both genera. Furthermore, patterns of response to temporal variability between sources suggest that recharge interval length may itself be an agent of selection; plants from the Mediterranean source generally survived best with frequent pulsing, even when either pulse amount or total water amount was held constant, 
whereas desert plants seemed to respond similarly across treatments.

\section{Pulsing regime and survival}

These results demonstrate that survival can be as strongly affected by inter-recharge duration as seasonal total water amounts, and that response to temporal variability may differ under high versus low total water. Lengthening the interval between recharge events shortened the survival of all sources except the desert forb, especially at high total water, indicating that the disadvantage of long intervals is more important to survival than the potential advantage of the corresponding larger individual pulses in our design. This also suggests that an interpulse (sensu Goldberg and Novoplansky 1997) period when resources were not available for uptake was likely reached for most plants under the longer recharge intervals.

Our survival patterns are consistent with previous work on Kansas grasslands that found higher species turnover rates with larger, less frequent rain events (Knapp et al. 2002). They are only somewhat consistent with previous work on New Mexico grasses which also found that survival into a recharge interval was worse when the preceding pulse was larger; however, this was found for the desert, not mesic, congeneric species tested (Novoplansky and Goldberg 2001b). At the other extreme, we found frequent, small pulses were usually only advantageous when seasonal totals were large. It is likely that when small, these "surface pulses" evaporated before they could be used by the plant. Thus, ironically, these short recharge intervals may have corresponded with the longest actual interpulse lengths.

\section{Pulsing regime and growth}

Treatments explained growth patterns much less than survival patterns, and recharge interval was usually more important than total water. However, the general pattern predicted for survival was also seen for growth, i.e., that the lowest growth during the first month of treatments (in some cases, negative) was found under the longest intervals, and was best under short intervals. This is consistent with work done on mesic grassland species that found decreased photosynthetic rates and annual primary productivity when inter-rainfall periods were lengthened (Knapp et al. 2002). Exceptions to this in our experiment included the forb, which had decreased growth with frequent, small pulses. Also, Vulpia receiving large, infrequent pulses seemed eventually able to regain biomass through leaf production, although not enough to make a significant difference in final biomass. On the whole, recharge interval-total water combinations did not necessarily yield the same pattern as was seen for survival, thus for this experiment, survival was not simply the ultimate expression of decreased growth.
In our experiment, final above- and belowground biomass reflected less responsiveness to treatments than was measured by relative growth rates. This result for final biomass may be a consequence of analyzing data for plants that survived to the end or nearly the end of the experiment; therefore treatments may have selected for those individuals who, like the desert plants generally, were less sensitive to changes in water availability. Furthermore, the sample size may have been too small relative to the variation in growth between individuals.

\section{Source effects}

Several previous studies have compared response to water availability in plants from desert versus Mediterranean habitats, but few if any have specifically considered response to the temporal aspect of resources or mortality response to stress.

The prediction that the magnitude of response should be greater for Mediterranean species than for desert species was supported by our results, and most dramatically for Vulpia. Although some aspects of reproductive growth (Volis et al. 2001) and flowering phenology (Aronson et al. 1992) have been found to be more responsive to reductions in water availability for Mediterranean than for desert species, other studies have found more adaptive plasticity in desert species for rooting patterns (Taub and Goldberg 1996) and in root:shoot ratios (Aronson et al. 1992). We found neither adaptive plasticity (e.g., flowering phenology), nor growth/survival changes in our desert species in response to variations in water pulsing, suggesting that these species have a one-size-fits-all strategy under a given level of water, and that the differences between our two seasonal totals may not have been enough to stimulate a phenological response.

The difference between the Mediterranean and desert plants response may be related to size and evapotranspiration capacity, as suggested by Knapp and Smith (2001). As Mediterranean plants had greater mass than desert plants, one may argue that larger size made individuals more vulnerable to water stress; however, in this experiment, initially larger Mediterranean plants were more likely to survive to the end of the season, and initial size was a positive predictor of lifespan for Vulpia. Some research supports the theory that larger plants should survive between resource renewal events better than smaller plants (Donovan et al 1993, Donovan and Ehleringer 1994). Larger plants may be able to sacrifice parts, being modular in nature, potentially allowing them to survive longer into a recharge interval (Danin 1996). That size was predictive of lifespan for the grass, which is more modular than the forb, supports this hypothesis. However, if small size is due to past stress, one may expect the same individuals to have also initiated droughtadaptation traits, therefore resulting in a correlation between small size and survival into a period of drought (Novoplansky and Goldberg 2001b). 
The most likely explanation for the observed difference in responsiveness between the sources is that selection has favored a relatively conservative growth and survival strategies for the plants from desert sources that are neither as vulnerable nor as responsive to increases in total water amount or renewal frequency (Chapin 1991, Knapp and Smith 2001). Mediterranean plants, on the other hand, are adapted to shorter and more reliable pulse frequency and so may be more likely to have the capability of a plastic response in uptake rates and water-use efficiency at the cost of having mechanisms that protect it from drought (Alpert and Simms 2002). Therefore, they can take advantage of increases in water amount and renewal frequency, but will suffer more at long recharge intervals and/or low water. It should be noted that the mean annual precipitation at the Mediterranean source is nearly twice what plants received under the high water treatment. Therefore, the differences observed between treatments in this experiment may actually be an underestimate, assuming the Mediterranean plants are able to exploit further increases in water availability.

The analyses did not find any significant three-way interactions between source, recharge interval, and total water; however, the patterns in the data supported our prediction that, due to the presumed cost of stress adaptations, desert plants should outperform Mediterranean species under low water and/or long recharge intervals, but that short intervals and high water will favor Mediterranean species. For Vulpia, this meant that the desert species had better survival to reproduction than the Mediterranean species under both low total water and long intervals, but was inferior at high total water with short intervals. However for Erodium, the switching in hierarchy between desert and Mediterranean species was even more emphasized due to the corresponding increase in survival in the desert Erodium at large, infrequent pulses, as mentioned above. It should be noted that increased survival in desert species at low total water and long recharge intervals cannot be explained by differences in root allocation, as root:shoot ratio did not differ between sources, and Mediterranean populations had greater belowground biomass.

Which species survived best has potential implications for population dynamics, since a plant with an appropriate pulse-response strategy would become dominant in a mixed stand; an outcome that could be mistaken for competitive superiority (sensu Tilman 1982), but which in fact could be explained simply in terms of the abiotic environment [sensu Grime $(1979,2001)$ and Goldberg and Novoplansky (1997)]. The two-phase resource hypothesis suggests that in pulse-driven systems, potentially better competitors such as the large, fast-growing, Mediterranean populations will not have a competitive advantage if they do not survive the recharge intervals. However, in those cases where size did influence survival, competition has a greater potential to affect survival between pulses. Conversely, without experimental manipulation of density, one cannot assume that at high resource levels, mortality of a "less competitive" species is necessarily attributable to competitive exclusion by the "more competitive" species.

It is important to note that providing the same size pulse (but with different total water amounts and therefore interval lengths) did not yield the same survival rates in plants from either Mediterranean population, or for the desert forb. Had this been so, we would not have observed the apparent switch in survival ranking between low water and long intervals with high water and short intervals, as the amount of water they were receiving in each case per watering event was the same. Although these patterns were non-significant statistically, they provide some post hoc support for our emphasis on recharge interval and total amounts of water in the design of this research. The interconnectedness of pulse size, interval length, and total water makes testing their relative importance difficult at best.

\section{Conclusions}

This work indicates the potential for local adaptation to intra-seasonal temporal variation in water availability, as distinct from response to total annual amounts. The length of inter-recharge intervals can be as or more important than total annual amount of water for determining both survival and growth of individual annual forbs and grasses, especially for those species adapted to high precipitation and frequent resource renewal rates. If plants are sufficiently stressed so as not to have positive growth reactions to pulses (as was seen for the grass) or if size is not a good predictor of survival between pulses (as was seen for the desert species), then dynamics that influence growth during pulses will be less important than a plant's ability to survive long periods between pulses. To the extent that periods of low resource availability are determined by abiotic factors such as evaporation and percolation, this work supports the hypothesis that competition may be less important than stress tolerance in arid habitats (Grime 2001).

Acknowledgements We would like to thank Karen Vitkay and Shi Qian for technical help. Shachar Shem-Tov and Laurie Flowers provided invaluable comments on this manuscript, and it was much improved by edits from two anonymous reviewers. Thanks also to Cindy Tejral of the Denver Botanic Gardens for proofing the manuscript. This research was funded by the Fulbright Foundation (US-Israel) and the Blaustein International Center for Desert Research (Ben Gurion University of the Negev, Israel). This is publication no. 398 of the Mitrani Department of Desert Ecology, Ben Gurion University of the Negev.

\section{References}

Alpert P, Simms EL (2002) The relative advantages of plasticity and complexity in different environments: when is it good for a plant to adjust? Evol Ecol 16:285-297

Aronson J, Kigel J, Shmida A, and Klein J (1992) Adaptive phenology of desert and Mediterranean populations of plants grown with and without water stress. Oecologia 89:17-26 
Bilbrough CJ, Caldwell MM (1997) Exploitation of springtime ephemeral $\mathrm{N}$ pulses by six Great Basin plant species. Ecology 78:231-243

Bowman WD (1992) Inputs and storage of nitrogen in winter snowpack in an alpine ecosystem. Arct Alp Res 24:211-215

Cable DR (1969) Competition in the semidesert grass-shrub type as influenced by root systems, growth habits, and soil moisture extraction. Ecology 50:27-38

Campbell BD, Grime JP (1989) A comparative study of plant responsiveness to the duration of episodes of mineral nutrient enrichment. New Phytol 112:261-267

Chapin FS (1991) Integrated responses of plants to stress: a centralized system of physiological responses. Bioscience 41:29-36

Danin A (1996) Plants of desert dunes. Springer, Berlin Heidelberg New York

Donovan LA, Ehleringer JR (1994) Water stress and use of summer precipitation in a Great Basin shrub community. Funct Ecol 8:289-297

Donovan LA, Mausberg J, Ehleringer JR (1993) Seedling size and survival for Chrysothamus nauseosus. Great Basin Nat 53:237245

Easterling DR, Meehl GA, Parmesan C, Changnon SA, Karl TR, Mearns LO (2000) Climate extremes: observation, modeling, and impact. Science 289:2068-2074

Ehleringer JR, Phillips SL, Schuster WSF, Sandquist DR (1991) Differential utilization of summer rains by desert plants. Oecologia 88:430-434

Evenari M, Shanan L, Tademor N (1982) The Negev: challenge of a desert, 2nd edn. Harvard University Press, Cambridge, Mass.

Fay PA, Carlisle JD, Knapp AK, Blair JM, Collins SL (2000) Altering rainfall timing and quantity in a mesic grassland ecosystem: design and performance of rainfall manipulation shelters. Ecosystems 3:308-319

Feinbrun-Dothan, N. (1986) Flora Palaestina, part four. The Israel Academy of Sciences and Humanities, Jerusalem

Gebauer LE, Schwinning S, Ehleringer JR (2002) Interspecific competition and resource pulse utilization in a cold desert community. Ecology 83:2602-2616

Goldberg DE, Novoplansky A (1997) On the relative importance of competition in unproductive environments. J Ecol 85:409

Grime JP (1979) Plant strategies and vegetation processes. Wiley, Chichester

Grime JP (2001) Plant strategies, vegetation processes and ecosystem properties. Wiley, Chichester

Knapp AK, Smith MD (2001) Variation among biomes in temporal dynamics of aboveground primary production. Science 291:481-484
Knapp AK, Fay PA, Blair JM, Collins SL, Smith MD, Carlisle JD, Harper CW, Danner BT, Lett MS, McCarron JK (2002) Rainfall variability, carbon cycling, and plant species diversity in a mesic grassland. Science 298:2202-2205

Lodge DJ, McDowell WH, McSwiney CP (1994) The importance of nutrient pulses in tropical forests. Trees 9:384-387

Miao SL, Bazzaz FA (1990) Responses to nutrient pulses of two colonizers requiring different disturbance frequencies. Ecology 71:2166-2178

Nilsen ET, Sharifi MR (1997) Carbon isotopic composition of legumes with photosynthetic stems from Mediterranean and desert habitats. Am J Bot 84:1707-1713

Novoplansky, Goldberg (2001a) Effects of water pulsing on individual performance and competitive hierarchies in plants. J Veg Sci 12:199-208

Novoplansky A, Goldberg DE (2001b) Interactions between neighbor environments and drought resistance. J Arid Environ 47:11-32

Noy-Meir I (1973) Desert ecosystems: environment and producers. Annu Rev Ecol Syst 4:25-51

Reynolds JF, Kemp PR (2002) Shrub-grass transitions in the Jornada Basin in the past century: experimental and modeling evidence do no support climate hypotheses. Presentation. Pulse Workshop, ESA, Tempe, Ariz. (http://ag.arizona.edu/research/ schwinn/WStalks.html)

SAS (1990) SAS/STAT user's guide. SAS Institute, Cary, N.C.

Schwinning S, Ehleringer JR (2001) Water use trade-offs and optimal adaptations to pulse-driven arid ecosystems. J Ecol 89:464-480

Sternberg M, Shoshany M (2001) Aboveground biomass allocation and water content relationships in Mediterranean trees and shrubs in two climatological regions in Israel. Plant Ecol 157:173-181

Taub DR, Goldberg D (1996) Root system topology of plants from habitats differing in soil resource availability. Funct Ecol $10: 258-264$

Tilman D (1982) Resource competition and community structure. Princeton University Press, Princeton, N.J.

Volis S, Mendlinger S, Ward D (2001) Differentiation in populations of Hordeum spontaneum Koch along a gradient of environmental productivity and predictability: plasticity in response to water and nutrient stress. Biol J Linn Soc 75:301-312

Volis S, Mendlinger S, Ward D (2002) Adaptive traits of wild barley plants of Mediterranean and desert origin. Oecologia 133:131138

Welzin JF, McPherson GR (2000) Implications of precipitation redistribution for shifts in temperate savanna ecotones. Ecology 81:1902-1913

Zohary M (1972) Flora Palaestina, part two. The Israel Academy of Sciences and Humanities, Jerusalem 